sequent misdeeds. An addictive feature of these monographs is the pair of contrasting world maps provided. showing the animal"s range "before" and "after" the onset of globe-trotting: the temptation. which I suspect few will resist, is to thumb ahead for a furtive peep to discover whether your favourite species suffers the stigma of far-flung black blobs scattered improperly across the "after" maps. The text itself is an enjoyable blend of biology and history, and is written in a precise and scholarly style. Although the author does not dwell on the implications for ecological theory of the effects of different immigrants on their new habitats. his text draws attention to the extraordinary interest of the process of invasion, and the many "unnatural" experiments that have been inadvertently established worldwide.

The history of three canids illustrates the scope of the book and the variation in the examples it documents. Red foxes were introduced to Australia in the late nineteenth century, in numbers generally no greater than two's and three's, by would-be huntsmen. Their progress can be charted in detail year by year from local records, until they are now widespread to

Animals and plants first annually. (Incidentally. British foxes were also shipped across to populate the eastern United States. and foxes from Spain were imported to bolster the numbers in Britain.) Then there is the raccoon dog. which originated in the Far East. For them, the scale of the operation was quite different. Between 1929 and 1967. 8.651 were released in European Russia by those with an eye on their pelts - in 1947 alone, 1.147 gravid females were let loose in the Caucasus. Each of these cases differs from that of the dingo, which was probably shipped to Australia some 3,000 years ago and so must soon qualify for honorary citizenship.

Although essentially a reference volume, this book has the "Guinness Book of Records" type of appeal to a browser. Apart from serving its main purpose, it will doubtless provide an abundance of worthwhile "Did you know ...?" gambits for both amateur and professional naturalists.

David $W$. Macdonald is in the Department of Zoology. University of Oxford. South Parks Road, Oxford OXI 3PS, UK.

\section{Botanical spread}

\section{Brian Mathew}

A Guide to the Vegetation of Britain and Europe. By Oleg Polunin and Martin Walters. Oxford University Press: 1985. Pp.284.£17.50, \$25.

AMID the dense rash of wild-flower books dealing with the flora of Britain and Europe at the species level, it is refreshing to be presented with a volume devoted to whole communities of plants. Polunin and Walters are probably accurate in claiming that this is the first attempt to bring together all the information on the subject at a layman's level, although, as they acknowledge, there are many other detailed works covering individual countries or regions.

Accordingly, a helpful bibliography has been included, divided into vegetation types, for those who wish to pursue any interesting points raised in the text. For internal reference, the reader is also well provided for, with indexes to Latin names, English names and plant communities, and a useful glossary (although I was surprised to find no mention, here or in the index, to the commonly used term "downland"). Conservationists, who now tend to put as much emphasis upon the preserva-

- Flowering Plants of the World, consultant editor V. H. Heywood, which was published in 1978 by Oxford University Press and has been out of print, has been re-issued by Croom Helm in Britain and Prentice-Hall in the United States. Price is $£ 19.95, \$ 39.95$. tion of habitats as of individual species, will find much useful material is provided, and there is a descriptive list of the Nature Reserves and National Parks throughout Europe.

The opening chapters deal with the allimportant subjects of soils and climates, which have a great bearing on the plant cover, and there is an interesting summary of the history of Europe's vegetation from the earliest fossil records onwards. The bulk of the book consists of 14 chapters devoted to different regional zones Arctic, Mediterranean, Central Europe and so on - and, within these, there are subdivisions down to communities with examples of the species to be found in them. The text is supported by many good line drawings and a few rather poorly reproduced monochrome photographs; the latter, however, are more than compensated for by the 110 excellent colour plates of vegetation types.

The authors have faced a difficult task, and it is not surprising that the book may appear bitty at first sight. As with most aspects of the botanical world, the demarcation lines are often ill-defined and there is much overlap, for example between maquis and garigue, with several different types of each of these. To have presented an over-classified statement of the situation would have led to many inaccuracies, and it is to the particular credit of Walters and Polunin, given the intended audience of their book, that they have struck the right balance between the superficial and the overly learned.

Brian Mathew is a Principal Scientific Officer in the Herbarium, Royal Botanic Gardens, Kew, Richmond, Surrey TW9 3AB, UK.

\section{Michael J. Bean}

International Wildlife Law. By Simon Lyster. Grotius, Llandyssul, Dyfed SA44 4BQ. UK: 1985. Pp.470. Hbk £25, \$37; $p b k £ 12, \$ 17.50$.

ThE earliest efforts at international cooperation in the conservation of living resources date back well into the nineteenth century. Since then, the number of international treaties and agreements aimed at conserving wildlife has grown steadily. Not until Simon Lyster's book, however, has anyone tried to offer a comprehensive analysis of that body of law. The result is a compelling display of legal scholarship that should reward scientists interested in policy matters and conservationists around the world.

This is a book by a British lawyer about international conservation law. It escapes, however, the trap of appealing only to a narrow audience of similar specialists. After an introductory chapter that provides a layman's overview of certain general principles and characteristics of international law, Lyster turns his attention to a series of wildlife treaties. For each of these he offers some historical background, includ. ing a discussion of the problems that the treaty was intended to address, a detailed analysis of the terms of the treaty, and an assessment of the treaty's actual implementation and effects.

The most remarkable aspect of the book is its sheer scope. It is not limited to the treaties of a particular country or geographical region, and reaches out across ocean barriers to encompass the Convention on Nature Protection and Wildlife Preservation in the Western Hemisphere (1940), the African Convention on the Conservation of Nature and Natural Resources (1968), a pact of 1969 among Andean nations for the conservation of the vicuna, an agreement of 1973 among circumpolar nations for the conservation of the polar bear, numerous European treaties for the conservation of birds and other wildlife, and yet other initiatives.

The most thorough analysis in the book is devoted to four treaties of the 1970 s that Lyster calls "the centrepiece of international wildlife law": the Convention on Wetlands of International Importance Especially as Waterfowl Habitat (1971); the Convention Concerning the Protection of the World Cultural and Natural Heritage (1972); the Convention on International Trade in Endangered Species of WiId Fauna and Flora (1973); and the Convention on the Conservation of Migratory Species of Wild Animals (1979). The complete texts of these and eight other treaties are reprinted in full in 